\title{
Do continuous and intermittent exercises sets induce similar cardiovascular responses in the elderly women?*
}

\author{
Úrsula Veloso $^{1}$, Walace Monteiro ${ }^{2}$ and Paulo Farinatti ${ }^{1}$
}

\begin{abstract}
There is a lack of information about elderly acute cardiovascular responses in the elderly during exercise involving different muscle groups and strategies of load/repetition interaction (LRI) in continuous and intermittent sets. The purpose of this study was to compare heart rate (HR), systolic blood pressure (SBP), rate-pressure product (RPP) and quality of exercise performance (QEx) of upper and lower body exercises (arms abduction and hip flexion) in different situations of LRI. Twelve healthy women aged 65 to 85 years old volunteered to this study. The subjects performed both exercises at 12 maximal repetitions workload, continuously ( 2 sets of 12 reps) and alternately (4 sets of 6 reps). HR was measured with a cardiotachometer and SBP through auscultation technique at the end of the last repetition of each set. The exercises were recorded in video to evaluate QEx. At least for the selected exercises, LRI did not influence QEx. However, SBP and RPP values for the intermittent sets were significantly higher than for continuous situations $(\mathrm{p}<0.05)$. The authors concluded that continuous sets seem to be associated to greater cardiovascular stress in elder subjects, mainly because of SBP responses during the exercise.
\end{abstract}

Key words: Cardiovascular physiology. Strength. Calisthenics. Elderly.

1. Laboratório de Aptidão Física e Promoção da Saúde - Universidade do Estado do Rio de Janeiro. Laboratório de Fisiologia do Exercício - Núcleo do Instituto de Ciências de Atividade Física da Aeronáutica (NUICAF-Aeronáutica).

2. Laboratório de Fisiologia do Exercício - Núcleo do Instituto de Ciências de Atividade Física da Aeronáutica (NUICAF-Aeronáutica). Programa de Pós-graduação em Educação Física - Universidade Gama Filho (PPGEF-UGF).

Received in 3/1/03

$2^{\text {nd }}$ version received in $11 / 2 / 03$

Approved in 12/4/03

Mail address:

Paulo Farinatti

Laboratório de Atividade Física e Promoção da Saúde - LABSAU

Rua São Francisco Xavier, 524, sala 8.133, bloco F, Maracanã

20550-013 - Rio de Janeiro, RJ

Tel.: (21) 2587-7847

E-mail: farinatt@uerj.br

\section{INTRODUCTION}

Among the physiological changes that occur with aging, strength reduction can be mentioned, with a marked influence in daily-life activities ${ }^{1-3}$. On the other hand, it is known that resistive exercises can increase or preserve muscular mass of elders, contributing to a decrease in orthopedic injuries and maintenance of functional independence $^{4,5}$. For the development of exercise programs for elders, one should be careful in considering training variables, such as frequency during the week, length of time, selection of exercises, number of sets and repetitions, intensity, and form of progression ${ }^{6,7}$. One of the aspects to be considered is the safety of the proposed activities, particularly on acute cardiovascular responses. For this purpose many authors have used assessment of heart rate (HR), blood pressure (BP), and rate-pressure product (RPP) as non-invasive indicators of cardiovascular overload during exercise ${ }^{8-12}$.

Factors such as workload, tension time, and muscular mass involved in the exercise are acknowledged as being able to influence cardiovascular responses during exercise ${ }^{13-}$ ${ }^{15}$. However, the available studies seem to focus basically weight-lifting exercises, on an individual basis. Classes of resistive exercises can also be an option to enhance strength, and are typically practiced by elders who seek to undergo exercise programs. In addition to the possibility of working on specific muscle groups, this is a type of activity that favors integration and socialization, which increases longterm compliance ${ }^{16}$. However, one could not find studies analyzing the influence of variations in the practice of exercises on acute cardiovascular responses in elders. For instance, a resource often used is to divide sets of repetitions over different exercises, which theoretically would delay localized fatigue. It is not known up to what point this would also influence acute behavior of cardiovascular variables.

Thus, the purpose of the study was to compare HR, SBP and RPP in exercises involving different muscle groups and strategies of load/repetition interaction in continuous and intermittent sets. One tried to determine if simple changes in the practice of exercises with no changes in loads could impact the magnitude of responses, thus influencing safety levels of the proposed activities. 


\section{MATERIAL AND METHODS}

Twelve healthy women aged 65 to 85 years old (mean $=$ $72 \pm 6$ years) volunteered to the study. For sample selection, the following criteria were met: a) regular practice of exercises for at least 3 months; b) body mass index $\leq 35$ $\mathrm{kg} / \mathrm{m}^{2}$, preventing overweight levels to compromise the quality of exercise performance; c) Par-Q questionnaire negative. For exclusion criteria, the following were considered: a) use of drugs that affected HR during exercise; b) bone-muscle-joint problems that limited the performance of the proposed exercises. All volunteers signed an informed consent form, as recommended by resolution 196/96 of the National Health Council, after approval of the Ethics Committee.

The developed protocol included two exercises, one for lower limbs (LLS), the other, for upper limbs (ULS). The exercises were performed under two different situations. In each one of them the volume of training was kept, with different number of continuous repetitions. Thus, in one situation, four sets of six repetitions (intermittent set) were performed, whereas in the other situation, two sets of twelve repetitions (continuous set) were performed. Therefore, it was considered as continuous set the performance without interruption of a given exercise. The intermittent set, by comparison, is the one in which the sequence is not followed, and the proposed exercises are alternated, even though the activity itself was not interrupted. The LLS exercise was hip unilateral flexion, with bent knees, from the standing position up to a $90^{\circ}$ angle between thigh and trunk. To maintain balance and standing posture, exercise was performed with the use of a bat in front of the body (figure 1). For ULS, the exercise was shoulder abduction up to a $90^{\circ}$ angle to the trunk, extended elbows and wrists in 'neutral position' (figure 2).

Prior to data collection, each subject performed a $12 \mathrm{MR}$ test to define the workload to be used in the exercise. Furthermore, a set for adaptation was also performed. Data was then collected on the two following days. For each individual, the order the exercises were performed and the type of sets were defined according to the Latin square technique. Each subject performed two sets of 12 repetitions each for each lower limb, alternating them with exercises for upper limbs in different days. There were no intervals between the exercises, in an attempt to duplicate the conditions typically found in gym classes.

In the two proposed situations, the following variables were assessed: HR, BP and quality of exercise performance (QEx). HR was measured continuously during the exercises with the use of a $\operatorname{Polar}^{\oplus}$ cardiotachometer, model Accurex Plus. BP was measured at the end of the last repetition of
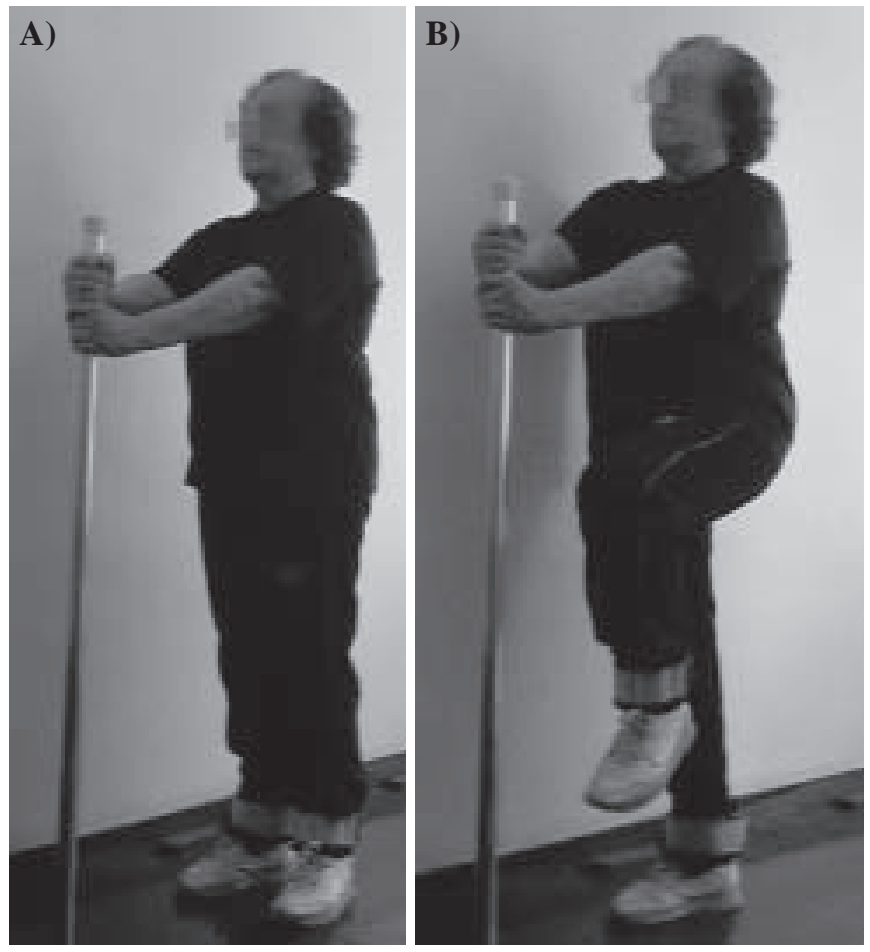

Fig. 1 -Exercise for lower limbs
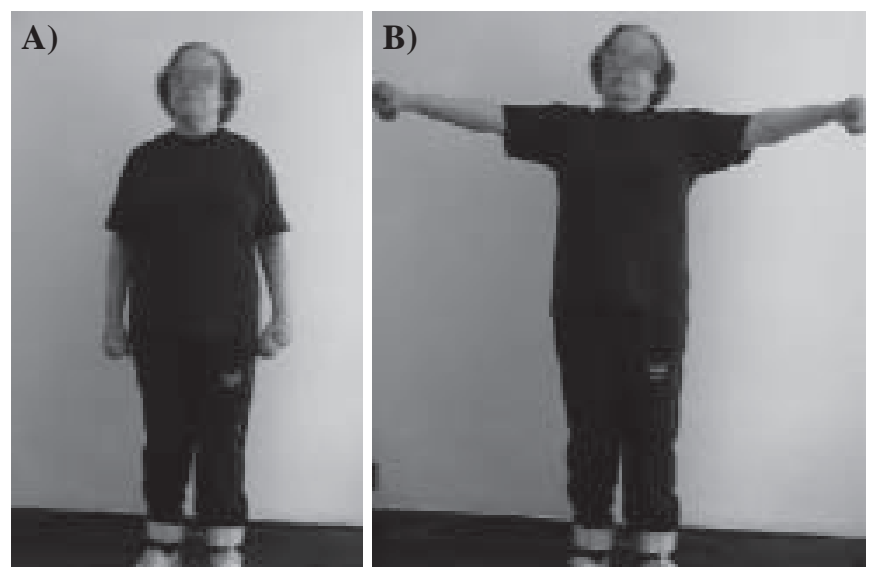

Fig. 2-Exercise for upper limbs

each set, with the use of a Tycos ${ }^{\oplus}$ sphygmotonograp and a Lithman $^{\circledR}$ stetoscope, model Classic II. For this purpose, the instrument was placed on the right arm prior to the performance of the exercises, and inflated at the end of the last repetition. Two evaluators made the measurement. While one held the BP recorder, the other inflate the instrument to measure BP level and listened to Korotkoff sound.

A concern to be clarified was about quality of exercise performance, which could be influenced by the type of set. In other words, to compare acute cardiovascular responses induced by the types of exercise performance, it would be 
necessary, before anything else, to have evidence that the performed exercise was not significantly different from the other. Otherwise, one would actually be comparing different activities. To assess QEx, the movements were filmed, and two evaluators scored it according to a scale especially designed for the study. The more defective the performance of the exercise, the higher the score on the scale (tables 1 e 2). The final score was the average of the scores from the two evaluators.

Statistical analysis involved the following procedures: a) to compare HR, BP and RPP results between the sets of a same number of repetitions, and between continuous and intermittent situations, one used a two-entry ANOVA, and the variables used were sets and type of performance; $b$ ) to check for inter-observer reliability and QEx consonance between the sets, Wilcoxon, and Spearman correlation tests were applied. For all cases, a 5\% level for type I error was required for statistical significance.

\section{TABLE 1}

Assessment scale for quality of exercise performance (lower limbs)

General impression of the performance (right posture) $1 \mathrm{pt}$ Use of undesired muscle groups to help performance $2 \mathrm{pt}$ Loss of performance rhythm during repetitions $2 \mathrm{pt}$ Inadequate range of motion during performance $3 \mathrm{pt}$ Undesired shift of the exercise performance plan $\quad 2$ pt

\section{RESULTS}

Initially, the impact of the proposed performance on QEx was assessed. After viewing the films, the scores given by the two evaluators were compared in the following situations: a) ULS and LLS exercises; b) continuous and intermittent sets. This strategy was used to assess intra-evaluator reliability on QEx assessment. As shown in tables 1 and 2 , no significant differences between the scores given in the different situations were found.

Once it was confirmed that the type of execution (continuous or intermittent) did not interfere in the quality of the proposed exercises, one moved on to assess data relat-

\section{TABLE 2}

Assessment scale for quality of exercise performance (upper limbs)

General impression of the

performance (right posture)

$1 \mathrm{pt}$

Use of the body to help the motion

(move trunk backwards)

$2 \mathrm{pt}$

Loss of performance rhythm

during repetitions

$2 \mathrm{pt}$

Inadequate range of motion

during performance

$3 \mathrm{pt}$

Undesired shift of the

exercise performance plan

$1 \mathrm{pt}$

Bend wrist during performance

\begin{tabular}{|c|c|c|}
\hline \multicolumn{3}{|c|}{$\begin{array}{c}\text { TABLE } 1 \\
\text { Intra-observers reliability }\end{array}$} \\
\hline Studied combinations & Wilcoxon & Spearman \\
\hline Upper limbs 6 repetitions - evaluator $1 \times 2$ & NS & $r=0.82$ \\
\hline Lower limbs 6 repetitions - evaluator $1 \times 2$ & NS & $r=0.81$ \\
\hline Upper limbs 12 repetitions - evaluator $1 \times 2$ & NS & $r=0.77$ \\
\hline Lower limbs 12 repetitions - evaluator $1 \times 2$ & NS & $r=0.86$ \\
\hline
\end{tabular}

TABLE 2

Correlation between 6 and 12 repetitions

\section{Studied combinations}

Upper limbs 6 rep x 12 rep - evaluator 1 Lower limbs 6 rep x 12 rep - evaluator 1 U pper limbs 6 rep $\times 12$ rep - evaluator 2 Lower limbs 6 rep x 12 rep - evaluator 2

$\begin{array}{cc}\text { Wilcoxon } & \text { Spearman } \\ \text { NS } & r=0.60 \\ \text { NS } & r=1.00 \\ \text { NS } & r=0.63 \\ \text { NS } & r=0.95\end{array}$

NS = not significant 


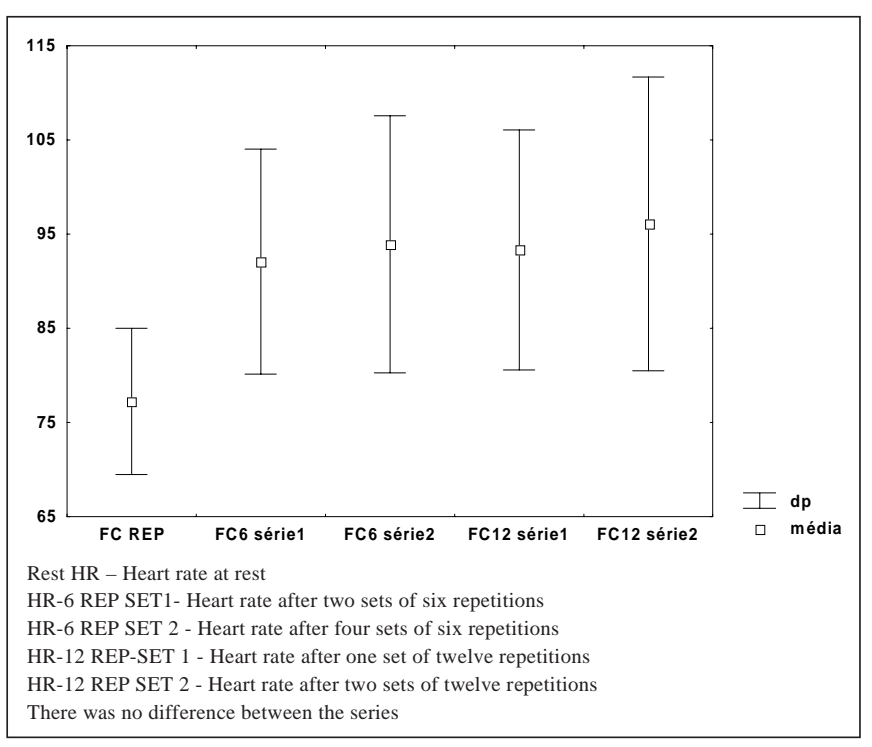

Fig. 3 - Heart rate response in continuous and intermittent exercises

ed to acute responses of cardiovascular variables. Thus, figures 3, 4 and 5 show ANOVA mean values and results for $\mathrm{HR}, \mathrm{SBP}$ and RPP, respectively, for the different performance situations. As one can see, there was no significant difference in HR for sets with the same number of repetitions, the same going for the two performance situations (continuous and intermittent). As to BP responses, there were significant differences when the first set was compared to the second in both situations, or when the second continuous set was compared to the second intermittent set. On the other hand, the same was not seen when one compared the first continuous set with the first intermittent set. Finally, significant RPP differences were found when comparing sets with the same number of repetitions, as well as for the different forms of performance.

\section{DISCUSSION}

When prescribing exercises, assessment of the dynamic responses to effort is fundamental, particularly when one considers safety. In this context, literature has shown that double-product is a good non-invasive indicator to estimate oxygen demand by the myocardium, at least for continuous aerobic activities ${ }^{9,10,17}$. For non-continuous activities, such as resistance training, RPP measure is not correlated to oxygen demand by the myocardium. This, however, does not prevent this measure from being valued in assessing heart overload. Under any perspective one appreciates this subject, higher rate-pressure product during exercise is due to more significant heart rate, systolic volume, heart output, and, in some cases, systemic resistance; therefore, higher the cardiovascular stress. Thus, institutions such as the

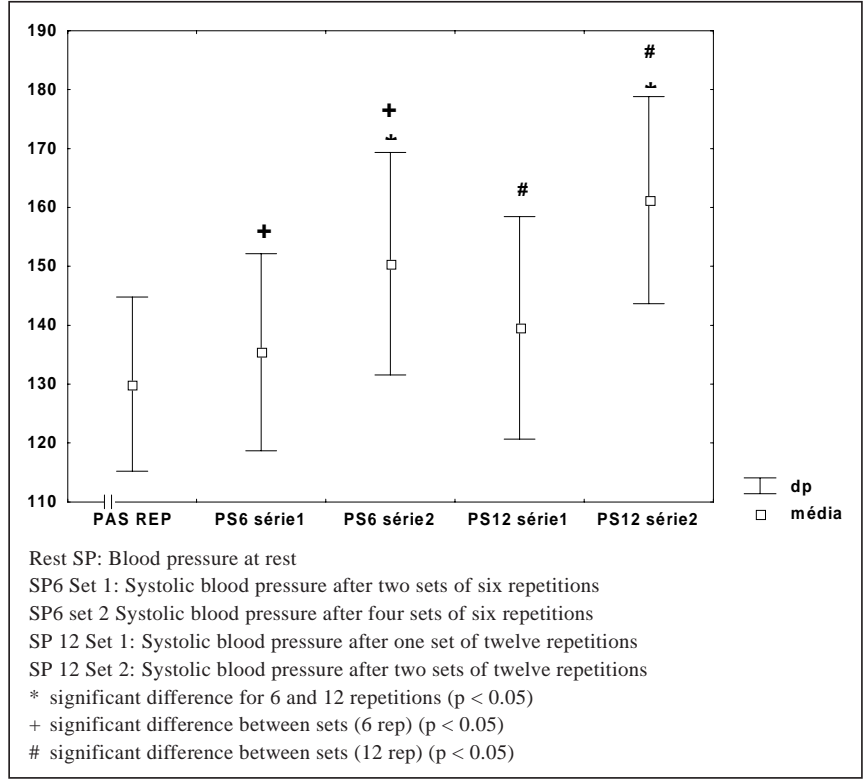

Fig. 4-Blood pressure response in continuous and intermittent exercises

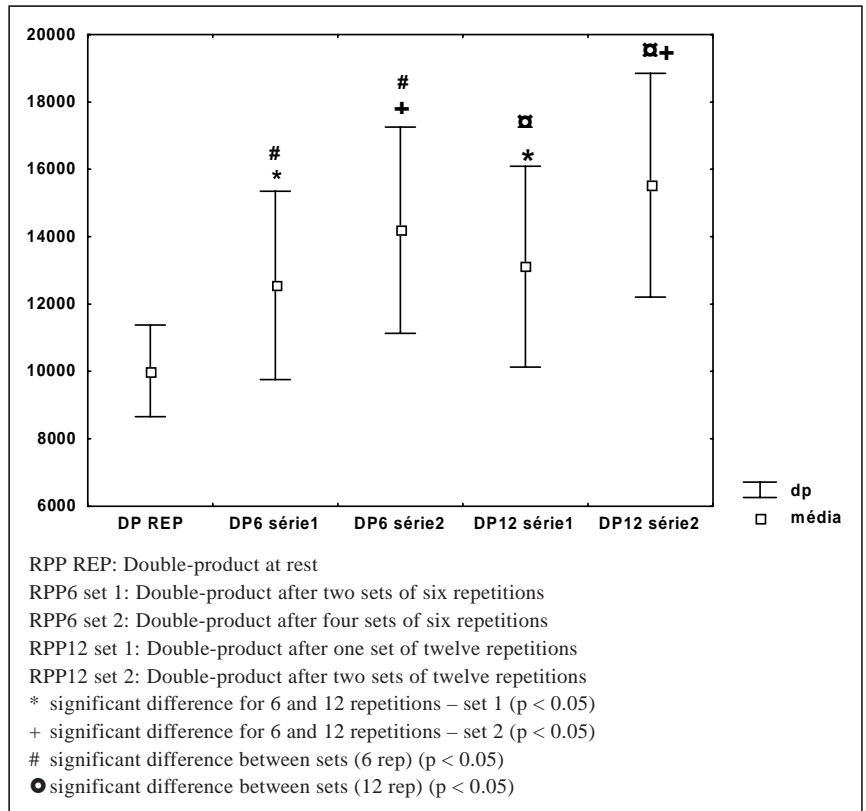

Fig. 5 -Double-product in continuous and intermittent exercises

American College of Sports Medicine ${ }^{7}$ consider this variable the best indicator of cardiac demand in weight-lifting programs.

For determining RPP in this study, an existing limitation is the blood pressure measuring technique. Auscultation method tends to underestimate blood pressure values for resistive exercises, as they rapidly fall at end of muscle contraction. Therefore, intra-arterial measurement is considered the golden standard to measure blood pressure. 
However, being an invasive procedure, there might be high risks for the participant. Thus, upon ethical considerations, the use of this technique is not advised in trials with healthy subjects ${ }^{18,19}$. Even though the error margin is higher and it is harder to duplicate results, the auscultatory method is easier to apply, with smaller risk. The assumption is that the tendency to underestimate absolute blood pressure values, particularly SBP one, is kept throughout the exercise. Thus this method allows identification, at least by comparison, of cardiovascular demand from the exercises ${ }^{20}$. In other words, through auscultation it is possible to state that cardiovascular overload caused by an exercise may be bigger than the one caused by another, even though one does not accurately measure absolute BP and RPP values. Other studies used auscultation to compare blood pressure responses from different activities involving resistive exercises, under the same assumption ${ }^{21-24}$.

We did not find studies comparing cardiovascular responses in continuous and intermittent exercises sets practiced by elders in gym classes. Literature has shown more concern in addressing the effects of resistive exercises practiced in an appropriate equipment. Some examples are the studies of Overend et al. ${ }^{11}$ and Smolander et al. ${ }^{25}$, who focused their attention on cardiovascular stress of youngsters and elders during isokinetic and isometric exercises, respectively. The results of this study showed there was no significant HR differences between continuous and intermittent sets with similar or different number of repetitions, showing that the proposed workout situations did not influence the response of this variable. However, it was expected that HR increased according to the mobilized muscular mass and with tension time the musculature was subjected to ${ }^{26,27}$. One of the aspects that may have influenced the results was the continuity in performing both exercises: in spite of the continuous or intermittent nature of each one of them, there was actually no interval between the sets, with a total performance time similar for the same relative intensity (maximum resistance percentage).

However, significant differences were observed for SBP when the first set was compared to the second, in both situations, or when the second continuous set was compared to the second intermittent set. On the other hand, the same was not seen when the first continuous set was compared to the first intermittent set. These date suggest SBP would be influenced by the way exercises are performed, with the intermittent workout requiring a smaller cardiovascular demand. This may be due because of difference in the time of arterial occlusion, which was systematically higher in the continuous than in the intermittent sets. This possibility has also been mentioned in other studies involving assessment of the tension time in resistive exercises ${ }^{14,28}$.
RPP results show significant differences between the sets with the same number of repetitions, as well as for the different types of performance. These data confirm the results available in the literature, which associate cardiac overload to skeletal musculature recovery time ${ }^{8,27}$. In our study, one could check that, in the second sets of both types of performance, RPP was significantly higher that in the first sets. As to the total workload, for the same cluster of mucles, tension time was smaller in the intermittent than in the continuous sets, even though total effort time was similar in both types of workout. As it has been said, the different types of workout are related to a varied arterial occlusion time for the same cluster of muscles, which may add to higher RPP values in the continuous workout. This possibility may be important for prescribing exercises for elders: the option for intermittent series, regardless of the load, may enhance training safety.

A simultaneous assessment of HR, SBP and RPP shows, in addition, that the later was more sensitive to SBP than $\mathrm{HR}$ variations. A possible explanation is the fact that $\mathrm{HR}$ changes are slower than SBP changes PAS ${ }^{8,15,27,28}$. Thus, HR values may not properly reflect cardiovascular overload from the exercise, particularly in elderly populations, as there is less variation in HR range in elders than in youngsters. Therefore, the monitoring of this variable should be considered when prescribing exercises for elders, particularly those with hard-to-control blood pressure, and it seems to be advisable the use of strategies that minimize its increase during the performance of exercises.

\section{CONCLUSION}

The presented results allow to conclude that: a) at least for the selected exercises, types of performance did not influence QEx; b) RPP values seem to be more sensitive to SBP and HR variations, in both types of exercise studied; c) cardiovascular demand, expressed by RPP, seems to be higher in continuous than in intermittent sets; d) HR did not change in the different proposed situations, but the same was not true for RPP, which may suggest this may be a more sensitive cardiovascular overload indicator in such activities. Finally, it is to be said that studies on acute physiologic responses in elders who practice gym exercises are rare. Further investigations to better understand these responses are desirable. To better disclose the influence of the different types of workout in the assessed variables, further studies should be carried out, with different exercises and new forms of load/repetition interventions. It would be also interesting to control variables with intervening potential, such as blood lactate and maximum resistance percentage, which indicate the relative intensity of the effort employed. 


\section{REFERENCES}

1. Häkkinen K, Häkkinen A. Neuromuscular adaptations during intensive strength training in middle-aged and elderly males and females. Electromyogr Clin Neurophysiol 1995;35:137-47.

2. Phillips WE, Haskell W. Muscular fitness - Easing the burden of disability for elderly adults. J Aging Phys Activity 1995;3:261-89.

3. Fontera WE, Hughes VA, Fielding RA, Fiatarine MA, Evans WJ, Roubenoff R. Aging of skeletal muscle: a 12-yr longitudinal study. J Appl Physiol 2000;88:1321-6.

4. Hurley B, Roth S. Strength training in the elderly: effects on risk factors for age-related diseases. Sports Med 2000;30:249-68.

5. Rubenstein LZ, Josephson KR, Trueblood PR, Loy S, Harker JO, Pietruszka FM, et al. Effects of a group exercise program on strength, mobility, and falls among fall-prone elderly men. J Gerontol A Biol Sci Med Sci 2000;55:317-21.

6. Mazzeo RS, Cavanagh P, Evans WJ, Fiatarone M, Hagberg J, McAuley E, et al. American College of Sports and Medicine. Position stand exercise and physical activity for older adults. Med Sci Sports Exerc 1998; 30:992-1008

7. American College of Sports Medicine. ACSM's Guidelines for exercise testing and prescription. $6^{\text {th }}$ ed. Baltimore: Lippincott Williams \& Wilkins, 2000

8. Fardy PS. Isometric exercise and cardiovascular system. Phys Sports Med 1981;9:43-56.

9. Micheletti P, Macchi G, Finulli P, Belleri M. Cardiac effects of exhausting isometric muscular contraction in trained and endurance athletes. $G$ Ital Cardiol 1990;20:148-57

10. Boutcher SH, Stocker D. Cardiovascular responses to light isometric and aerobic exercise in 21 to 59 years old males. Eur J Appl Physiol 1999;80:220-6

11. Overend T, Versteegh T, Thompson E, Birmingham T, Vandervoort A Cardiovascular stress associated with concentric and eccentric isokinetic exercise in young and older adults. J Gerontol 2000;55:177-82.

12. Farinatti PTV, Assis BFCB. Estudo de freqüência cardíaca, pressão arterial e duplo-produto em exercícios contra-resistência e aeróbio contínuo. Rev Bras Atividade Física e Saúde 2000;5:5-16.

13. Haslam DRS, McCartney N, McKelvie RS, MacDougall JD. Direct measurements of arterial blood pressure during formal weightlifting in cardiac patients. J Cardiopulm Rehabil 1988;8:213-25.
14. Sale DG, Moroz DE, McKelvie RS, MacDougall JD, McCartney N. Comparison of blood pressure response to isokinetic and weight-lifting exercise. Eur J Appl Physiol 1993;67:115-20.

15. Gotshall RW, Gootman J, Byrnes WC, Fleck SJ, Valovich TC. Noinvasive characterization of the blood pressure response to the double-leg press exercise. J Exerc Physiol 1999;2:1-6.

16. Van Normam KA. Exercise programming for older adults. Champaign: Human Kinetics, 1995.

17. Mayo J, Kravitz L. A review of the cardiovascular responses to resistance exercise of healthy young and older adults. J Strength and Cond Research 1999;13:90-6.

18. Raftery EB. Direct versus indirect measurement of blood pressure. J Hipertens Suppl 1991;9:10-2.

19. Perloff D, Grim C, Flack J, Frohlich E, Hill M, McDonald M. Human blood pressure determination by sphygmomanometry. Circulation 1993; 88:2460-7.

20. Polito M, Farinatti PTV. Considerações sobre as medidas da pressão arterial em exercícios contra resistência. Rev Bras Med Esporte 2003; 9:25-33.

21. Featherstone JF, Holly RG, Amsterdam EA. Physiologic responses to weight lifting in coronary artery disease. Am J Cardiol 1993;71:287-92.

22. Louhevaara V, Smolander J, Aminoff T, Korhonen O, Shen N. Cardiorespiratory responses to fatiguing dynamic and isometric hand-grip exercise. Eur J Appl Physiol 2000;82:340-4.

23. Jürimäe T, Jürimäe J, Pihl E. Circulatory response to single circuit weight and walking training session of similar energy cost in middle-age overweight females. Clin Physiol 2000;20:143-9.

24. Westcott W, Howes B. Blood pressure response during weight training exercise. Nat Strength Cond Assoc J 1983;5:67-8.

25. Smolander J, Aminoff T, Korhonen I, Tervo M, Shen N, Korhonen O, et al. Heart rate and blood pressure responses to isometric exercise in young and older men. Eur J Appl Physiol 1998;77:439-44.

26. Seals DR, Washburn RA, Hanson PG, Painter PL, Nagle FJ. Increased cardiovascular response to static contraction of larger muscle groups. J Appl Physiol 1983;54:434-7.

27. Benn SJ, McCartney N, McKelvie RS. Circulatory responses to weight lifting, walking, and stair climbing in older males. J Am Geriatr Soc 1996;44:121-5.

28. McCartney N. Acute responses to resistance training and safety. Med Sci Sports 1999;31:31-7. 